\title{
Covid-19: environmental health officers and retired doctors step up to fill contact tracing void
}

\author{
Elisabeth Mahase
}

The BMJ

Hundreds of environmental health professionals have offered their time and expertise to help with contact tracing in England, Wales, and Northern Ireland, in the hope of getting the covid-19 outbreak in the UK under control.

More than 400 signed up to the Chartered Institute of Environmental Health (CIEH) voluntary register, which has been shared with Public Health England and the governments in Wales and Northern Ireland.

Meanwhile, a team of retired doctors and public health experts in Sheffield, frustrated by the lack of contact tracing, have set up their own community initiative - combining contact tracing with support for those who need to self-isolate.

The moves come as health secretary Matt Hancock announced that the government would reintroduce contact tracing of people who have had symptoms of covid-19, supported by increased testing. ${ }^{1}$

Despite the World Health Organization repeatedly emphasising the importance of contact tracing, the UK abandoned the practice in March, arguing that when the number of cases rises it becomes less effective and resources are more effectively used elsewhere. $^{2}$

\section{"Making excuses"}

This decision has been widely criticised by doctors and public health experts who have pointed to countries such as South Korea, which used testing and contact tracing to control the outbreak. Speaking to The BMJ, Allyson Pollock, professor of public health and co-director of Newcastle University Centre of Research Excellence in Regulatory Science, said the government was making excuses.

"It was an excuse because they had only done 3500 contacts by the time they stopped on the 12 March. It's a pathetic excuse," she said.

Pollock said the government has, through cuts to local authorities and the Health and Social Care Act 2012, "decimated, fragmented, and carved out the local communicable disease response and that is why they do not have contact tracing on the ground."

She said, "You can only get on top of a national epidemic by having local control and local responses. Two weeks ago, there were no cases in places like South Tyneside, Blackpool, Hartlepool, and the Isle of Wight. That's exactly when you need to go in. Three weeks ago, there were really no cases in nursing homes and that's when they should have put in the prevention measures. That's how you get on top of this.

"Now they need rapidly to rebuild that capacity in local health bodies and to integrate that with other teams like GPs and environmental health professionals."

That is what the CIEH is hoping environmental health professionals can help with.

\section{Skills and knowledge}

Gary McFarlane, CIEH Northern Ireland director, told The BMJ, "When this crisis started we realised that there may be a significant professional resource that found themselves unable to work. We also recognised the skills and knowledge that environmental health professionals have to offer and that could be deployed in a number of key areas to support national efforts to respond to the crisis."

The institute has created a register with all its members who wish to volunteer to carry out tasks like contact tracing. "We've been in conversations with the key public health agencies in England, Wales, and Northern Ireland. We've made our volunteer register available to them all," McFarlane said.

The Welsh government has confirmed that council environmental health officers will be deployed as part of a mass community contact tracing drive in the planned next phase of coronavirus response efforts. Meanwhile, Public Health England medical director Yvonne Doyle told The BMJ, "Plans on scaling up contact tracing are being agreed, including how many people we will need, and we are talking to the CIEH and local authority colleagues as part of the development of those plans."

\section{Sheffield pilot}

While discussions are still ongoing a team of retired doctors and public health experts in Heeley and Meersbrook, Sheffield, have launched a pilot to test whether they can carry out contact tracing in collaboration with a GP practice.

The initiative involves a small team of trained volunteers calling people referred by the practice and asking them for a list of people they have been in contact with. The volunteers then call those contacts and give them the government advice on isolating. If local testing is available, they also signpost people to the service if appropriate. In addition, the team wants to provide some support to those isolating, so are offering a daily phone call to check in on the person. 
Speaking to The BMJ, Bing Jones, a former associate specialist in haematology, said the pilot will test whether this system is feasible. If it is successful, he thinks it will be easily scalable as they have been inundated with volunteers willing to help.

Both Scotland and Northern Ireland also look set to reintroduce contact tracing, with the latter starting a pilot next week. ${ }^{3}$

A spokesperson for the Scottish government said they are "engaged in a significant expansion of testing capacity to support a test, trace, isolate approach and to expand surveillance will be a crucial part of any moves to lift the lockdown measures in the future."

1 lacobucci G. Covid-19: UK pledges to reintroduce contact tracing to fight virus. $B M$ 2020;369:m1591. 10.1136/bmj.m1591 32317295

2 Department of Health and Social Care. Policy paper: coronavirus action plan: a guide to what you can expect across the UK. 3 March 2020. www.gov.uk/government/publications/ coronavirus-action-plan/coronavirus-action-plan-a-guide-to-what-you-can-expect-acrossthe-uk.

3 McCormack J. Coronavirus: contact tracing pilot to start in NI next week. April 2020. www. bbc.co.uk/news/uk-northern-ireland-52397772.

Published by the BMJ Publishing Group Limited. For permission to use (where not already granted under a licence) please go to http://group.bmj.com/group/rights-licensing/ permissions 